\title{
Pt-Catalyzed Reduction of Carboxamides Using Hydrosilanes
}

Key words

platinum

reduction

hydrosilanes

carboxamides

amines

SYNFACTuth

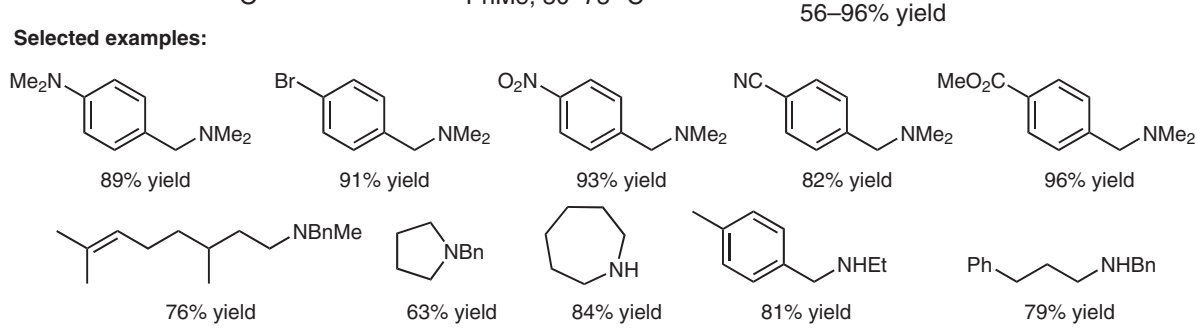

Mechanistic proposal:

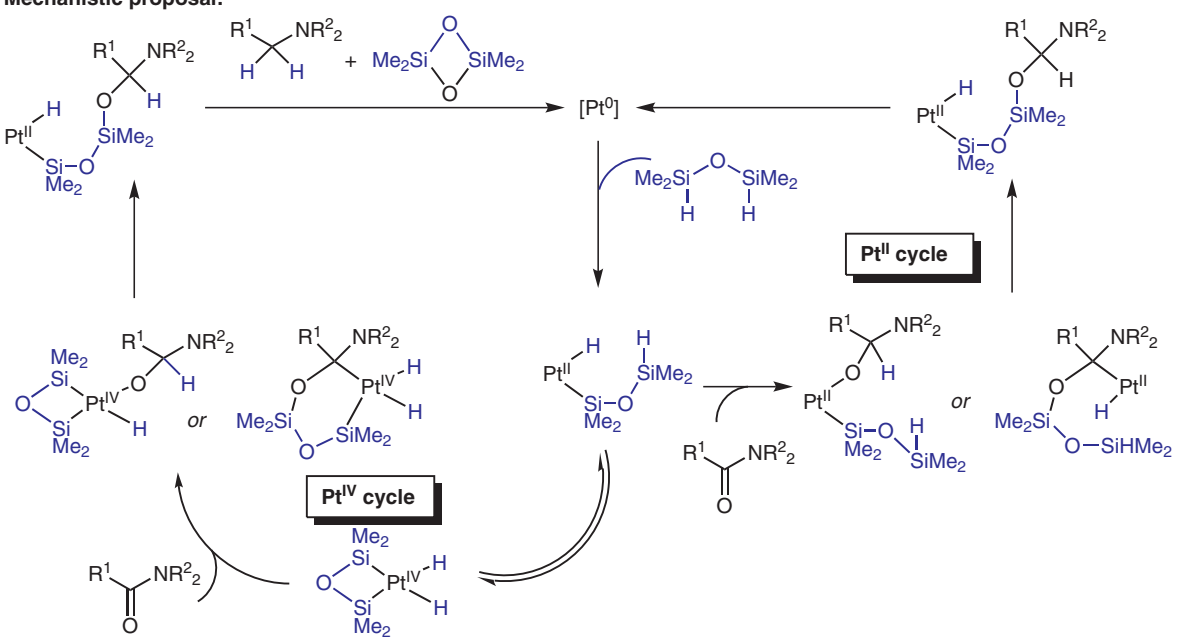

Significance: In this comprehensive article the platinum-catalyzed reduction of carbamides using hydrosilanes is described in detail. The reaction is highly chemoselective and proceeds with a remarkably high tolerance towards functional groups that are also prone to reduction, including cyano, ester and even nitro groups.
Comment: The key feature of this reaction is the 'dual $\mathrm{Si}-\mathrm{H}$ effect' in which two proximate $\mathrm{Si}-\mathrm{H}$ groups cooperatively promote the reduction reaction. Inexpensive and readily available disiloxanes, such as TMDS, can be used. The use of polymethylhydrosiloxane (PHMS) has the advantage that the silicone and platinum species can easily be removed from the product. 